Research Article

\title{
Investigation of the Effects of Steam Injection on Equilibrium Products and Thermodynamic Properties of Diesel and Biodiesel Fuels
}

\author{
Jean Paul Gram Shou $\mathbb{D}^{1},{ }^{1}$ Marcel Obounou, ${ }^{1}$ Timoléon Crépin Kofané, ${ }^{2}$ \\ and Mahamat Hassane Babikir ${ }^{1}$ \\ ${ }^{1}$ Laboratory of Energy and Electronics and Electrical Systems, Department of Physics, Faculty of Science, University of Yaoundé I, \\ Yaoundé, P.O. Box: 812, Cameroon \\ ${ }^{2}$ Laboratory of Mechanics, Materials and Structures, Department of Physics, Faculty of Science, University of Yaoundé I, \\ Yaoundé, P.O. Box: 812, Cameroon
}

Correspondence should be addressed to Jean Paul Gram Shou; jpgram1085s@yahoo.fr

Received 23 December 2019; Revised 14 May 2020; Accepted 1 August 2020; Published 3 September 2020

Academic Editor: Thanos Megaritis

Copyright (C) 2020 Jean Paul Gram Shou et al. This is an open access article distributed under the Creative Commons Attribution License, which permits unrestricted use, distribution, and reproduction in any medium, provided the original work is properly cited.

\begin{abstract}
The effects of steam injection on combustion products and thermodynamic properties of diesel fuel, soybean oil-based biodiesel (NBD), and waste cooking oil biodiesel (WCOB) are examined in this study by considering the chemical equilibrium. The model gives equilibrium mole fractions, specific heat of the exhaust mixtures of 10 combustion products, and adiabatic flame temperatures. The results show that the mole fractions of carbon monoxide $(\mathrm{CO})$ and carbon dioxide $\left(\mathrm{CO}_{2}\right)$ decrease with the steam injection ratios. Nitric oxide (NO) mole fractions decrease with the steam injections ratios for lean mixtures. The specific heat of combustion products increases with the steam injection ratios. The equilibrium combustion products obtained can be used to calculate the nonequilibrium values of NO in the exhaust gases using some existing correlations of NO kinetics.
\end{abstract}

\section{Introduction}

Fossil-based fuels derived from crude oil are the main sources of energy for internal combustion engines worldwide in general and in Cameroon in particular. However, combustion in internal combustion engines is a major source of pollutant emissions. More severe environmental restrictions have been put into effect in many countries worldwide due to the growing concern about environmental issues. In addition, the use of fossil-based fuels is still dominant in almost all internal combustion engines despite the fact that the resources of the fossil-based fuels are depleting rapidly. Thus, researchers carry out studies on combustion in internal combustion engines and alternative fuels. In this regard, biodiesel could be considered as an alternative fuel to fossil diesel to meet the growing fuel demand and the severe environmental norms. Biodiesel is produced from wider feedstock by transesterification, microemulsion, dilution, and pyrolysis. Rapeseed, soybean, and palm oils have been largely preferred as edible raw materials for the production of biodiesel worldwide [1]. Biodiesel has gained prominence as an attractive fuel because it is biodegradable, nontoxic, environmentally friendly, and free from sulfur and aromatic contents [2]. The diesel engine operating with biodiesel can decrease carbon monoxide (CO), hydrocarbons (HC), and smoke emissions while increasing nitrogen oxides $\left(\mathrm{NO}_{x}\right)$ [3-5]. The biodiesel properties are very close to the ones of diesel. However, the shortcomings of biodiesel are higher viscosity, density, cetane number, flash point, poor low-temperature properties and lower volatility, energy content, and oxidative and storage stability in comparison to the diesel fuel [6]. Higher cloud point and pour point, higher nitrogen oxide emissions, injector coking, engine compatibility, and higher 
engine wear are also the shortcomings of biodiesel which affect the combustion characteristics [7]. The poor lowtemperature properties of biodiesel are an obstacle to its utilization in cold weather conditions [8]. The differences in chemical properties of fuels affect the combustion process development, which lead to the alteration of performance and emissions of engine [9]. Biodiesels are formed from many different classes of saturated and unsaturated fatty acids, which form their physical and chemical properties [10]. Higher viscosity results in higher spray penetration into the combustion chamber, which is very important to enhance air-fuel mixing quality especially for big and slow engines with large open combustion chambers, but there are more adverse impacts for small and fast engines such as poor fuel atomization, larger droplet size, bad mixing quality, incomplete combustion, and lower combustion efficiency, which contribute to decreasing the engine performance and increasing the exhaust emissions [11]. Biodiesel combustion is difficult to model because of the diversity of its sources and complexity in molecular structure [12-16]. Chemical equilibrium model is a better estimation for a combustion model assuming that the combustion products are at a chemical equilibrium in a high-temperature combustion. The combustion products react together to produce and remove each species at equal rates, and consequently, the net change in species composition remains constant at a given condition [17]. Chemical equilibrium models are used in thermodynamic simulations of internal combustion engines [18]. A simple model including only six species of the products, namely, carbon dioxide $\left(\mathrm{CO}_{2}\right)$, water $\left(\mathrm{H}_{2} \mathrm{O}\right)$, nitrogen $\left(\mathrm{N}_{2}\right)$, oxide $\left(\mathrm{O}_{2}\right)$, carbon monoxide $(\mathrm{CO})$, and hydrogen $\left(\mathrm{H}_{2}\right)$, has been defined by Heywood [19]. Gonca [20] investigated the effects of steam injection on performance and nitric oxide (NO) emissions of a diesel engine running with ethanoldiesel blend. In his study, various ethanol-diesel blends were evaluated depending on the steam/air ratios by means of constituted solving schema based on chemical equilibrium. Ngayihi Abbe et al. [21] carried out a numerical study to compare four biodiesel surrogates using a zero-dimensional thermodynamic model involving a chemical equilibrium combustion model. A chemical equilibrium model was used by Ust and Kayadelen [22]. In their study, 10 combustion products were used to predict the equilibrium and thermodynamic properties in an $\mathrm{H}_{2} \mathrm{O}$ injected combustion system at various $\mathrm{H}_{2} \mathrm{O}$ rates. They neglected the $\mathrm{CO}$ and $\mathrm{H}_{2}$ formations in lean mixtures. They formed their equation systems for lean and rich mixtures separately. Rakopoulos et al. [23] performed a two-zone thermodynamic model for combustion and emissions formation in a direct injection diesel engine. They used a chemical equilibrium scheme involving 11 species of combustion products for calculating the constituents in exhaust gases. Diotallevi [24] developed a multi-zone thermodynamic model of a diesel engine for $\mathrm{NO}_{x}$ formation. He created a chemical equilibrium scheme by considering 10 combustion products. The nonlinear system of equations created was solved using an iterative method developed by the author using the Matlab program. Mourya and Roy [25] performed a study on the combustion modelling of a diesel engine operating using jatropha biodiesel and diesel engine blends according to a chemical equilibrium model. The $\mathrm{C}$ program and Mathematica software developed by the authors were used to solve their equations. Kayadelen [26] developed a multi-featured model for estimation of the mole fractions of 14 equilibrium combustion products, thermodynamic properties and constant-pressure adiabatic flame temperature of fuels, surrogates, and fuel additives. He constituted his equation systems for lean and rich mixtures separately. $\mathrm{CO}$ and $\mathrm{H}_{2}$ mole fractions were neglected in lean mixtures. The nonlinear equation systems were solved using both Newton-Raphson and Gauss-Seidel methods. Some equilibrium computer programs exist like GASEQ [27] and Chemical Equilibrium with Applications (CEA) of NASA [28]. However, GASEQ software neglects the effects of dissociations on the specific heat of the combustion products. Consequently, noticeable errors may result in engine performance calculations. On the other hand, CEA of NASA necessitates adiabatic flame temperature or enthalpy of combustion to be given. Important differences are reported between the specific heat results of GASEQ and CEA of NASA particularly at high temperatures. In literature, there is a lack of studies carried out on the effects of steam injection on equilibrium products and thermodynamic properties of diesel and biodiesel fuels. Nevertheless, the equilibrium combustion products can be used to calculate the nonequilibrium NO emissions in exhaust gases. The present model takes into account the effect of combustion products dissociations with temperature on specific heat of the gas mixture. The adiabatic flame temperature or combustion enthalpy is not needed as an input, but they can be calculated by the model. The main purpose of the present study is to investigate the effects of steam injection on equilibrium products and thermodynamic properties of diesel fuel, soybean oil-based biodiesel (NBD), and waste cooking oil biodiesel (WCOB). For this purpose, the solving schema of the combustion model based on a chemical equilibrium was developed for diesel and biodiesel fuels. The nonlinear system of equations is solved using Newton-Raphson and Gauss-Seidel methods. The diesel and biodiesel with chemical formulae $\mathrm{C}_{14.09} \mathrm{H}_{24.78}$ [29], $\mathrm{C}_{18.74} \mathrm{H}_{34.43} \mathrm{O}_{2}$ [29], and $\mathrm{C}_{18} \mathrm{H}_{36} \mathrm{O}_{2}$ [30] were used in this study to represent diesel fuel, soybean oil-based biodiesel (NBD), and waste cooking oil biodiesel (WCOBD), respectively.

\section{Theoretical Equilibrium Combustion Products Model}

2.1. Equilibrium Combustion Products. The combustion products are supposed to consist of ten species which are all assumed as ideal gases and they are defined by dissociation considerations as follows [31]:

$$
\begin{aligned}
& \frac{1}{2} \mathrm{H}_{2} \rightleftharpoons \mathrm{H}, \quad K_{1}=\frac{y_{7} p^{1 / 2}}{y_{6}^{1 / 2}}, \\
& \frac{1}{2} \mathrm{O}_{2} \rightleftharpoons \mathrm{O}, \quad K_{2}=\frac{y_{8} p^{1 / 2}}{y_{4}^{1 / 2}},
\end{aligned}
$$




$$
\begin{aligned}
& \frac{1}{2} \mathrm{H}_{2}+\frac{1}{2} \mathrm{O}_{2} \rightleftharpoons \mathrm{OH}, \quad K_{3}=\frac{y_{9}}{y_{4}^{1 / 2} y_{6}^{1 / 2}} \\
& \frac{1}{2} \mathrm{O}_{2}+\frac{1}{2} \mathrm{~N}_{2} \rightleftharpoons \mathrm{NO}, \quad K_{4}=\frac{y_{10}}{y_{3}^{1 / 2} y_{4}^{1 / 2}} \\
& \mathrm{H}_{2}+\frac{1}{2} \mathrm{O}_{2} \rightleftharpoons \mathrm{H}_{2} \mathrm{O}, \quad K_{5}=\frac{y_{2}}{y_{6}^{1 / 2} y_{6} p^{1 / 2}} \\
& \mathrm{CO}+\frac{1}{2} \mathrm{O}_{2} \rightleftharpoons \mathrm{CO}_{2}, \quad K_{6}=\frac{y_{1}}{y_{4}^{1 / 2} y_{5} p^{1 / 2}}
\end{aligned}
$$

where the unit of pressure $p$ is atmospheres and $K_{1}$ to $K_{6}$ are the equilibrium constants of the reactions. Olikara and Borman [32] have curve-fitted the equilibrium constants $K_{i}$ to tabulated JANAF thermochemical tables for the temperatures between $600 \mathrm{~K}$ and $4000 \mathrm{~K}$ and its values are calculated by using

$$
\log K_{i}=A_{i} \ln \left(\frac{T}{1000}\right)+\frac{B_{i}}{T}+C_{i}+D_{i} T+E_{i} T^{2},
$$

where the equilibrium constant curve-fit coefficients $A_{i}, B_{i}$, $C_{i}, D_{i}$, and $E_{i}$ are listed in Table 1 and presented by Ferguson [31].

\subsection{Equilibrium Combustion Model}

2.2.1. Low-Temperature Products. At low temperatures $(T<1000 \mathrm{~K})$ and for $\alpha / \gamma$ ratios less than one, the overall chemical reaction, which describes the combustion $(\phi<3)$ is given, as follows:

$$
\begin{aligned}
\varepsilon \phi \mathrm{C}_{\alpha} \mathrm{H}_{\beta} \mathrm{O}_{\gamma} \mathrm{N}_{\delta}+\left(0.21 \mathrm{O}_{2}\right. & \left.+0.79 \mathrm{~N}_{2}\right) \longrightarrow v_{1} \mathrm{CO}_{2}+v_{2} \mathrm{H}_{2} \mathrm{O} \\
& +v_{3} \mathrm{~N}_{2}+v_{4} \mathrm{O}_{2}+v_{5} \mathrm{CO}+v_{6} \mathrm{H}_{2}
\end{aligned}
$$

For the lean and stoichiometric combustion, it is assumed that there would be enough oxygen to oxidize all CO and $\mathrm{H}_{2}$ and that means $\mathrm{CO}$ and $\mathrm{H}_{2}$ are negligible. It can be noticed that the equilibrium composition is independent from temperature and pressure. It only depends on equivalence ratio $\phi$. The product composition is determined using atom balance equations. Products of wet combustion for the low temperature are given in Table 2. For the rich case, it is assumed that there is insufficient oxygen to oxidize all $\mathrm{CO}$ and $\mathrm{H}_{2}$, which means all the oxygen is consumed.

When writing atom balances, five unknowns and four equations are found. One more equation (10) is used and it depends on the equilibrium constant for the water-gas reaction given by Ferguson [31] for the range of temperatures between $400 \mathrm{~K}$ and $3200 \mathrm{~K}$ :

$$
\ln K=2.743-\frac{1.761}{t}-\frac{1.611}{t^{2}}+\frac{0.2803}{t^{3}}
$$

where $t=T / 1000$.

The equilibrium constant at constant pressure $\mathrm{K}$ of the water-gas reaction is expressed as follows:

$$
\mathrm{CO}_{2}+\mathrm{H}_{2} \rightleftharpoons \mathrm{CO}+\mathrm{H}_{2} \mathrm{O}, \quad K=\frac{\nu_{2} v_{5}}{v_{1} v_{6}} \text {. }
$$

2.2.2. High-Temperature Products. At higher temperatures $(T \geq 1000 \mathrm{~K})$ and for $\alpha / \gamma$ ratios less than one, the overall chemical reaction, which describes the combustion $(\phi<3)$, is given as follows:

$$
\begin{aligned}
& \varepsilon \phi \mathrm{C}_{\alpha} \mathrm{H}_{\beta} \mathrm{O}_{\gamma} \mathrm{N}_{\delta}+\left(0.21 \mathrm{O}_{2}+0.79 \mathrm{~N}_{2}\right)+x \mathrm{H}_{2} \mathrm{O} \longrightarrow \nu_{1} \mathrm{CO}_{2} \\
& +v_{2} \mathrm{H}_{2} \mathrm{O}+v_{3} \mathrm{~N}_{2}+v_{4} \mathrm{O}_{2}+v_{5} \mathrm{CO}+v_{6} \mathrm{H}_{2} \\
& +v_{7} \mathrm{H}+v_{8} \mathrm{O}+v_{9} \mathrm{OH}+v_{10} \mathrm{~N}
\end{aligned}
$$

where $v_{i}$ denotes the number of moles for each product, and $\alpha, \beta, \gamma$, and $\delta$ represent the atom numbers of carbon, hydrogen, oxygen, and nitrogen in the used fuel, respectively. For diesel fuel, $\gamma$ and $\delta$ are zeroes. When the product mole fraction composition is known at a given temperature, equivalence ratio, and pressure, the thermodynamic properties of interest such as enthalpy, entropy, specific volume, and internal energy can be computed.

The atom balance for various elements in equation (11), the constraint that the mole fraction of all the products adds up to one, the unknown total product moles $\mathrm{N}$, and the six dissociation equations (1)-(6) provided by the criteria of equilibrium among combustion products yield 11 equations for 11 unknowns, namely, unknown mole fractions $y_{i}$ and unknown total product moles $N$. After writing the mole fractions of the other combustion species with respect to the mole fractions of four independent variables $y_{3}, y_{4}, y_{5}$, and $y_{6}$, the following nonlinear equations are obtained:

$$
\begin{gathered}
f_{1}=C_{6} y_{4}^{1 / 2} y_{5}+C_{5} y_{4}^{1 / 2} y_{6}+y_{3}+y_{4}+y_{5}+y_{6} \\
+C_{1} y_{6}^{1 / 2}+C_{2} y_{4}^{1 / 2}+C_{3} y_{4}^{1 / 2} y_{6}^{1 / 2}+C_{4} y_{3}^{1 / 2} y_{4}^{1 / 2}-1=0 \\
f_{2}=2 C_{5} y_{4}^{1 / 2} y_{6}+2 y_{6}+C_{1} y_{6}^{1 / 2}+C_{3} y_{4}^{1 / 2} y_{6}^{1 / 2} \\
-d_{1}\left(C_{6} y_{4}^{1 / 2} y_{5}+y_{5}\right)=0 \\
f_{3}=2 C_{6} y_{4}^{1 / 2} y_{5}+C_{5} y_{4}^{1 / 2} y_{6}+2 y_{4}+y_{5}+C_{2} y_{4}^{1 / 2} \\
+C_{3} y_{4}^{1 / 2} y_{6}^{1 / 2}+C_{4} y_{3}^{1 / 2} y_{4}^{1 / 2}-d_{2}\left(C_{6} y_{4}^{1 / 2} y_{5}+y_{5}\right)=0 \\
f_{4}=2 y_{3}+C_{4} y_{3}^{1 / 2} y_{4}^{1 / 2}-d_{3}\left(C_{6} y_{4}^{1 / 2} y_{5}+y_{5}\right)=0 \\
C_{1}=\frac{K_{1}}{p^{1 / 2}}, \\
C_{2}=\frac{K_{2}}{p^{1 / 2}}, \\
C_{3} .
\end{gathered}
$$


TABLE 1: Olikara and Borman equilibrium constant curve-fit coefficients.

\begin{tabular}{cccccc}
\hline$i$ & $A_{i}$ & $B_{i}$ & $C_{i}$ & $D_{i}$ & $E_{i}$ \\
\hline 1 & 0.432168 & $-0.112464 \times 10^{5}$ & $0.267269 \times 10^{1}$ & $-0.745744 \times 10^{-4}$ & $0.242484 \times 10^{-8}$ \\
2 & 0.310805 & $-0.129540 \times 10^{5}$ & $0.321779 \times 10^{1}$ & $-0.738336 \times 10^{-4}$ & $0.344645 \times 10^{-8}$ \\
3 & -0.141784 & $-0.213308 \times 10^{4}$ & 0.853461 & $0.355015 \times 10^{-4}$ & $-0.310227 \times 10^{-8}$ \\
4 & $0.150879 \times 10^{-1}$ & $-0.470959 \times 10^{4}$ & 0.646096 & $0.272805 \times 10^{-5}$ & $-0.154444 \times 10^{-8}$ \\
5 & -0.752364 & $0.124210 \times 10^{5}$ & $-0.260286 \times 10^{1}$ & $0.259556 \times 10^{-3}$ & $-0.162687 \times 10^{-7}$ \\
6 & $-0.415302 \times 10^{-2}$ & $0.148627 \times 10^{5}$ & $-0.475746 \times 10^{1}$ & $0.124699 \times 10^{-3}$ & $-0.900227 \times 10^{-8}$ \\
\hline
\end{tabular}

TABLe 2: Products of wet combustion for $T<1000 \mathrm{~K}$.

\begin{tabular}{lccc}
\hline$i$ & Species & $\phi \leq 1$ & $\phi>1$ \\
\hline 1 & $\mathrm{CO}_{2}$ & $\alpha \phi \varepsilon$ & $\alpha \phi \varepsilon-\nu_{5}$ \\
2 & $\mathrm{H}_{2} \mathrm{O}$ & $\beta \phi \varepsilon+x$ & $\phi \varepsilon(\gamma-2 \alpha)+0.42+\nu_{5}$ \\
3 & $\mathrm{~N}_{2}$ & $0.79+\delta \phi \varepsilon / 2$ & $0.79+\delta \varphi \varepsilon / 2$ \\
4 & $\mathrm{O}_{2}$ & $0.21(1-\phi)$ & 0 \\
5 & $\mathrm{CO}$ & 0 & $\mathrm{~N}_{5}$ \\
6 & $\mathrm{H}_{2}$ & 0 & $0.42(\phi-1)-\nu_{5}$ \\
\hline
\end{tabular}

$$
\begin{aligned}
& C_{4}=K_{4}, \\
& C_{5}=K_{5} p^{1 / 2}, \\
& C_{6}=K_{6} p^{1 / 2}, \\
& d_{1}=\frac{\varepsilon \phi \beta+2 x}{\varepsilon \phi \alpha}, \\
& d_{2}=\frac{\varepsilon \phi \gamma+0.42+x}{\varepsilon \phi \alpha}, \\
& d_{3}=\frac{\varepsilon \phi \delta+1.58}{\varepsilon \phi \alpha} .
\end{aligned}
$$

The equivalence ratio $\phi$ and the molar fuel/air ratio $\varepsilon$ are expressed as follows:

$$
\begin{aligned}
& \phi=\frac{m_{f} / m_{a}}{\left(m_{f} / m_{a}\right)_{s},} \\
& \varepsilon=\frac{0.21}{\alpha-\gamma / 2+\beta / 4} .
\end{aligned}
$$

By letting $Y=\left(y_{3}, y_{4}, y_{5}, y_{6}\right)^{T}$ be the vector of the independent variables, $\delta Y=\left(\delta y_{3}, \delta y_{4}, \delta y_{5}, \delta y_{6}\right)^{T}$ the solution vector of the linear system, and $F$ the vector containing the functions $f_{3}, f_{4}, f_{5}$ and $f_{6}$, the system of nonlinear equations can be written in a single expression using vectors:

$$
F(Y)=\left[f_{3}(Y), f_{4}(Y), f_{5}(Y), f_{6}(Y)\right]=0 .
$$

The exact solution of the problem is $Y=Y^{(0)}+\delta Y^{(0)}$, which means

$$
F(Y)=F\left(Y^{(0)}+\delta Y^{(0)}\right)=0
$$

where $Y^{(0)}$ is a given rough initial guess for the solution. In the neighbourhoods of $Y^{(0)}$, the functions $f_{i}(Y)$ can be expanded in Taylor series and truncated after the first derivative. We obtain a set of linear equations for the vector $\delta Y^{(0)}$ that move each value $f_{i}\left(Y^{(0)}\right)$ closer to zero simultaneously:

$$
\mathfrak{I}\left(Y^{(0)}\right) \delta Y^{(0)}=-F\left(Y^{(0)}\right) .
$$

The Jacobian matrix $\mathfrak{I}$ is expressed as

$$
\Im\left(Y^{(0)}\right)=\left(\begin{array}{cccc}
\frac{\partial f_{1}\left(Y^{(0)}\right)}{\partial y_{3}} & \frac{\partial f_{1}\left(Y^{(0)}\right)}{\partial y_{4}} & \cdots & \frac{\partial f_{1}\left(Y^{(0)}\right)}{\partial y_{6}} \\
\frac{\partial f_{2}\left(Y^{(0)}\right)}{\partial y_{3}} & \frac{\partial f_{2}\left(Y^{(0)}\right)}{\partial y_{4}} & \cdots & \frac{\partial f_{2}\left(Y^{(0)}\right)}{\partial y_{6}} \\
\vdots & \vdots & \ddots & \vdots \\
\frac{\partial f_{4}\left(Y^{(0)}\right)}{\partial y_{3}} & \frac{\partial f_{4}\left(Y^{(0)}\right)}{\partial y_{4}} & \cdots & \frac{\partial f_{4}\left(Y^{(0)}\right)}{\partial y_{6}}
\end{array}\right) .
$$

The set of linear equations equation (29) is solved for $\delta Y(0)$ using Gauss-Seidel iterative method. The new approximated solution is calculated as $Y^{(1)}=Y^{(0)}+\delta Y^{(0)}$.

If $Y^{(1)}$ does not approximate the solution to the given tolerance, successive approximations of the solution are obtained as follows:

$$
\mathfrak{\Im}\left(Y^{(k)}\right) \delta Y^{(k)}=-F\left(Y^{(k)}\right) .
$$

The procedure is repeated until $\delta Y^{(k)}$ reaches a specified tolerance which leads to the values for $Y$ :

$$
Y=Y^{(k)}+\delta Y^{(k)} \text {. }
$$

The other dependent unknowns are expressed after determining the mole fractions $y_{3}, y_{4}, y_{5}$, and $y_{6}$ as follows:

$$
\begin{aligned}
& y_{1}=C_{6} y_{4}^{1 / 2} y_{5}, \\
& y_{2}=C_{5} y_{4}^{1 / 2} y_{6}, \\
& y_{7}=C_{1} y_{6}^{1 / 2}, \\
& y_{8}=C_{2} y_{4}^{1 / 2}, \\
& y_{9}=C_{3} y_{4}^{1 / 2} y_{6}^{1 / 2}, \\
& y_{10}=C_{4} y_{3}^{1 / 2} y_{4}^{1 / 2} .
\end{aligned}
$$


TABLe 3: Chemical and physical properties of test fuels.

\begin{tabular}{lccc}
\hline Fuel properties & Diesel [30] & NBD [30] & WCOB \\
\hline Density at $15^{\circ} \mathrm{C}\left(\mathrm{kg} \cdot \mathrm{m}^{-3}\right)$ & 853.7 & 881.4 & $865.19[36]$ \\
Kinematic viscosity at $40^{\circ} \mathrm{C}\left(\mathrm{mm}^{2} \cdot \mathrm{s}^{-1}\right)$ & 2.8271 & 4.2691 & $3.5[36]$ \\
$\mathrm{LHV}\left(\mathrm{kJ} \cdot \mathrm{kg}^{-1}\right)$ & 42640 & 37388 & $37000[31]$ \\
Oxygen (wt. \%) & 0.00 & 10.98 & 11.27 \\
Cetane number & 42.6 & 51.5 & $54[31]$ \\
Chemical formula & $\mathrm{C}_{14.09} \mathrm{H}_{24.78}$ & $\mathrm{C}_{18.74} \mathrm{H}_{34.43} \mathrm{O}_{2}$ & $\mathrm{C}_{18} \mathrm{H}_{36} \mathrm{O}_{2}[31]$ \\
\hline
\end{tabular}

TABLE 4: Standard specifications for biodiesel.

\begin{tabular}{lcc}
\hline Fuel properties & ASTM D6751 & EN 14214 [36] \\
\hline Density at $15^{\circ} \mathrm{C}\left(\mathrm{kg} \cdot \mathrm{m}^{-3}\right)$ & $880[37]$ & $860-900$ \\
Kinematic viscosity at $40^{\circ} \mathrm{C}\left(\mathrm{mm}^{2} \cdot \mathrm{s}^{-1}\right)$ & $1.9-6.0[37]$ & $3.5-5.0$ \\
Cetane number & Min. 47 [37] & Min. 51 \\
Flash point $\left({ }^{\circ} \mathrm{C}\right)$ & Min. 93 [37] & Min. 101 \\
Sulfur $\%(\mathrm{mg} / \mathrm{kg})$ & Max. 0.05 [30] & Max. 10 \\
Oxidation stability at $110^{\circ} \mathrm{C}(\mathrm{hr})$ & Min. 3 [37] & Min. 6 \\
\hline
\end{tabular}

TABLE 5: Comparison of the present model results with the ones obtained from CEA of NASA and GASEQ software for equilibrium combustion products of methane at $\phi=0.6$ and steam injection $10 \%$.

\begin{tabular}{|c|c|c|c|c|c|}
\hline$\phi=0.6$ & Model results & GASEQ results & CEA results & GASEQ relative error (\%) & CEA relative error $(\%)$ \\
\hline $\mathrm{CO}_{2}$ & 0.051506 & 0.05154 & 0.05151 & 0.066 & 0.066 \\
\hline $\mathrm{H}_{2} \mathrm{O}$ & 0.233920 & 0.23399 & 0.23385 & 0.029 & 0.029 \\
\hline $\mathrm{N}_{2}$ & 0.645559 & 0.64553 & 0.64553 & -0.005 & -0.005 \\
\hline $\mathrm{O}_{2}$ & 0.068353 & 0.06827 & 0.06827 & -0.122 & -0.122 \\
\hline $\mathrm{CO}$ & $1.328 \times 10^{-7}$ & $1.33 \times 10^{-7}$ & $3.27 \times 10^{-7}$ & -0.157 & -0.157 \\
\hline $\mathrm{H}_{2}$ & $2.419 \times 10^{-7}$ & $2.41 \times 10^{-7}$ & $2.41 \times 10^{-7}$ & -0.360 & -0.360 \\
\hline $\mathrm{H}$ & $1.269 \times 10^{-9}$ & $1.27 \times 10^{-9}$ & $1.27 \times 10^{-9}$ & 0.03 & 0.03 \\
\hline $\mathrm{O}$ & $1.506 \times 10^{-7}$ & $1.50 \times 10^{-7}$ & $1.50 \times 10^{-7}$ & -0.429 & -0.429 \\
\hline $\mathrm{OH}$ & $3.263 \times 10^{-5}$ & $3.39 \times 10^{-5}$ & $3.39 \times 10^{-5}$ & 3.751 & 3.751 \\
\hline NO & $6.278 \times 10^{-4}$ & $6.27 \times 10^{-4}$ & $6.27 \times 10^{-4}$ & -0.126 & -0.126 \\
\hline$C_{p}\left(\mathrm{~kJ} \cdot \mathrm{kg}^{-1} \cdot \mathrm{K}^{-1}\right)$ & 1.46488 & 1.45383 & 1.45383 & -0.76 & -0.76 \\
\hline$T_{\text {in }}(\mathrm{K})$ & 300 & 300 & 300 & 0.000 & 0.000 \\
\hline$T_{\text {ad }}(\mathrm{K})$ & 1482.3 & 1482.3 & 1482.3 & 0.000 & 0.000 \\
\hline
\end{tabular}

TABLE 6: Comparison of the present model results with the ones obtained from CEA of NASA and GASEQ software for equilibrium combustion products of methane at $\phi=1.2$ and steam injection $10 \%$.

\begin{tabular}{lccccc}
\hline$\phi=1.2$ & Model results & GASEQ results & CEA results & GASEQ relative error (\%) & CEA relative error (\%) \\
\hline $\mathrm{CO}_{2}$ & 0.063729 & 0.06368 & 0.06368 & -0.077 & -0.077 \\
$\mathrm{H}_{2} \mathrm{O}$ & 0.278173 & 0.27822 & 0.27822 & 0.017 & 0.017 \\
$\mathrm{~N}_{2}$ & 0.594799 & 0.59480 & 0.59480 & 0.00017 & 0.00017 \\
$\mathrm{O}_{2}$ & $5.826 \times 10^{-8}$ & $5.78 \times 10^{-8}$ & $5.78 \times 10^{-8}$ & -0.790 & -0.790 \\
$\mathrm{CO}$ & 0.031138 & 0.03119 & 0.03119 & 0.168 & 0.168 \\
$\mathrm{H}_{2}$ & 0.032106 & 0.03206 & 0.03206 & -0.144 & -0.144 \\
$\mathrm{H}$ & $2.988 \times 10^{-5}$ & $2.98 \times 10^{-5}$ & $2.98 \times 10^{-5}$ & -0.260 & -0.260 \\
$\mathrm{O}$ & $1.535 \times 10^{-8}$ & $1.53 \times 10^{-8}$ & $1.53 \times 10^{-8}$ & -0.345 & -0.345 \\
$\mathrm{OH}$ & $2.199 \times 10^{-5}$ & $2.95 \times 10^{-6}$ & $2.68 \times 10^{-6}$ & 2.679 & 2.57 \\
$\mathrm{NO}$ & $2.962 \times 10^{-6}$ & $2.95 \times 10^{-6}$ & 0.646096 & -0.394 & -0.394 \\
$C_{p}\left(\mathrm{~kJ} \cdot \mathrm{kg}^{-1} \cdot \mathrm{K}^{-1}\right)$ & 1.64592 & 1.63042 & 1.63042 & -0.95 & -0.95 \\
$T_{\mathrm{in}}(\mathrm{K})$ & 300 & 300 & 300 & 0.000 & 0.000 \\
$T_{\mathrm{ad}}(\mathrm{K})$ & 1919.3 & 1919.3 & 1919.3 & 0.000 & 0.000 \\
\hline
\end{tabular}

2.3. Thermodynamic Properties. At constant pressure, temperature variation has an effect on specific heat due to the dissociations of species at a high temperature. The effect of temperature on mole fractions should be considered during the equilibrium specific heat calculation differentiating with respect to temperature written as 

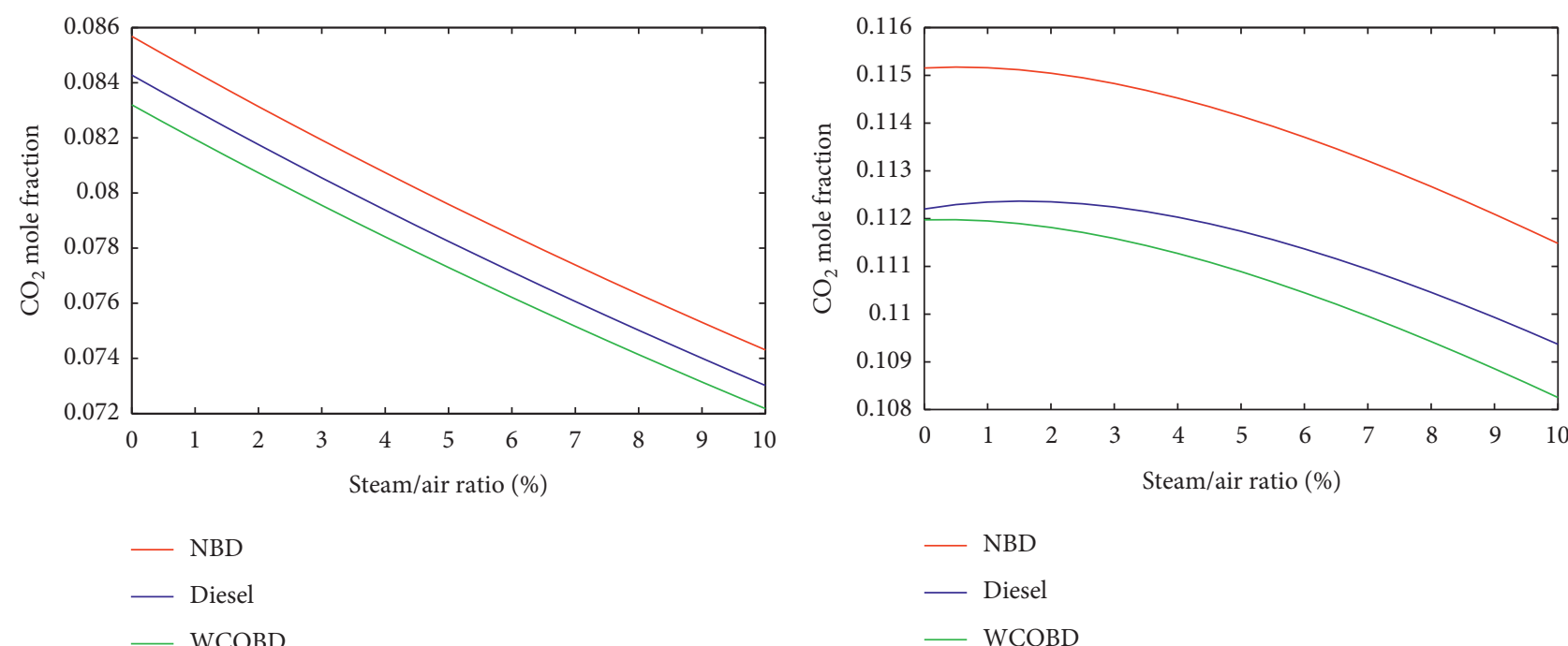

(a)

(b)

Figure 1: Variation of $\mathrm{CO}_{2}$ equilibrium mole fractions with steam injection ratios.

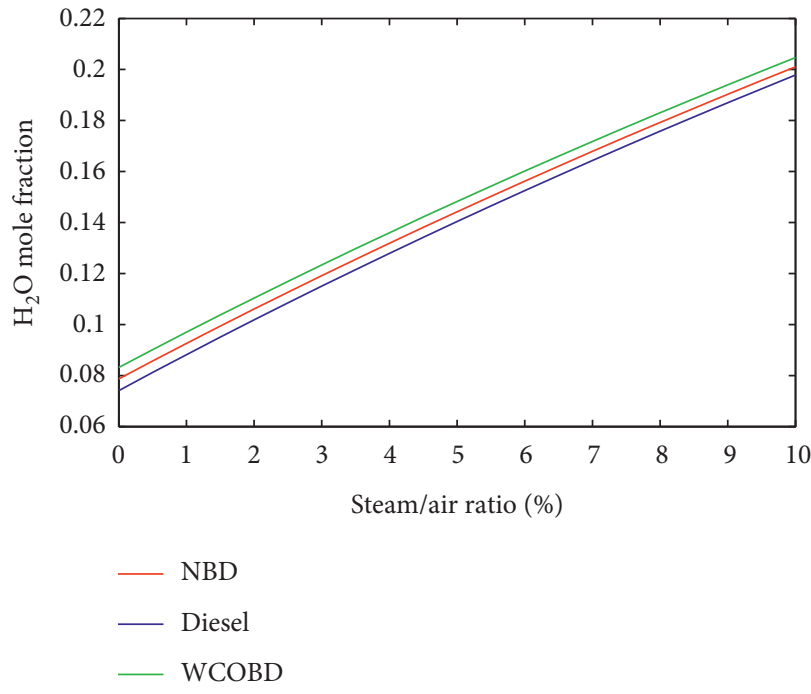

(a)

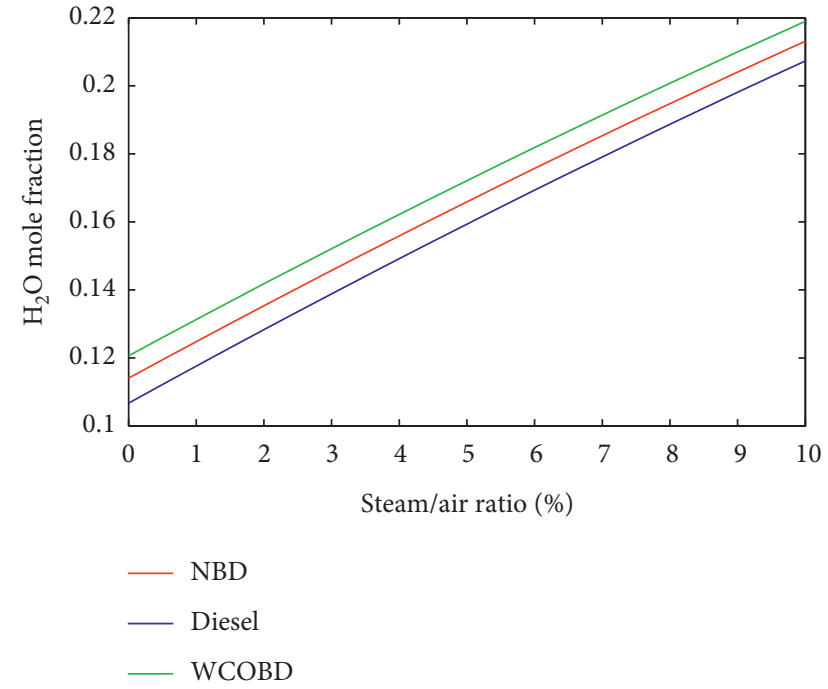

(b)

FIGURE 2: Variation of $\mathrm{H}_{2} \mathrm{O}$ equilibrium mole fractions with steam injection ratios.

$$
\begin{aligned}
\mathfrak{\Im}\left(Y^{(k)}\right) Y_{T}^{k} & =-F_{T}\left(Y^{(k)}\right), \\
F_{T} & =\frac{\partial F}{\partial T} \\
Y_{T} & =\frac{\partial Y}{\partial T} .
\end{aligned}
$$

The same procedure is used to solve equation (39). The results are used in computing the specific heat of the gas mixture in equation (46).

Gordon and McBride [33] proposed the expressions of molar specific heat at constant pressure $\bar{c}_{p, i}$ enthalpy $\bar{h}_{i}$ and entropy $\bar{s}_{i}^{0}$ values of each species that were curve-fitted to the tabulated JANAF thermochemical tables [34].
At constant pressure, enthalpy of the gas mixture $\bar{h}$ changes due to the dissociations because the mole fractions of the species change with temperature:

$$
\bar{h}=\sum_{i=1}^{10} y_{i} \bar{h}_{i}
$$

$$
\begin{aligned}
\bar{s} & =\sum_{i=1}^{10} R_{u} y_{i}\left(\frac{\bar{s}_{i}^{0}}{R_{u}}-\ln \left(\frac{y_{i} p}{p_{0}}\right)\right), \\
M & =\sum_{i=1}^{10} y_{i} M_{i},
\end{aligned}
$$




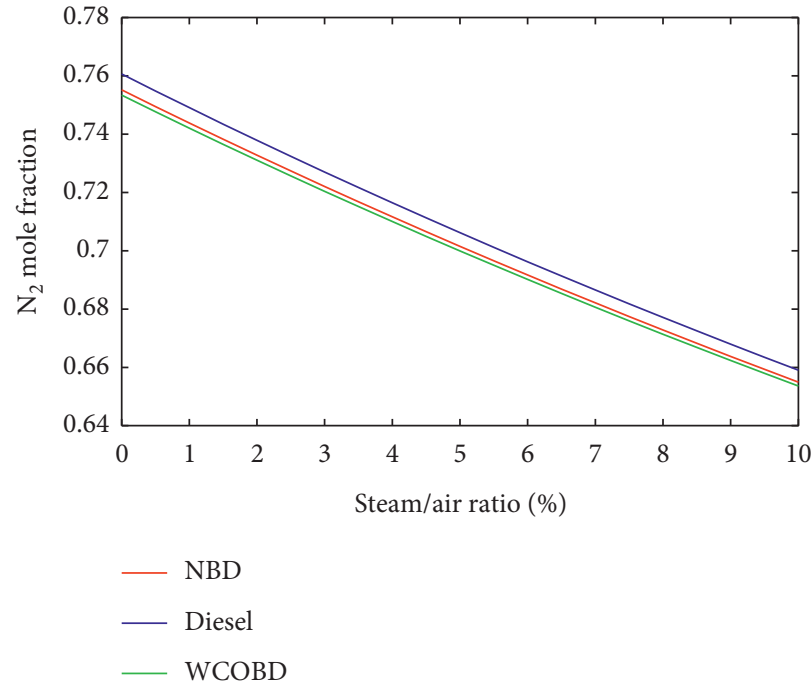

(a)

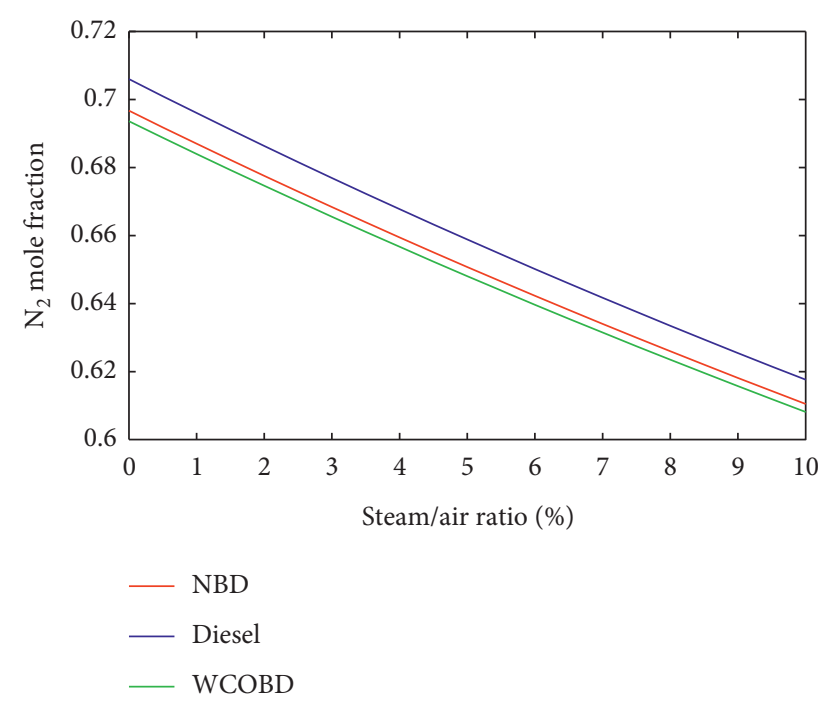

(b)

Figure 3: Variation of $\mathrm{N}_{2}$ equilibrium mole fractions with steam injection ratios.

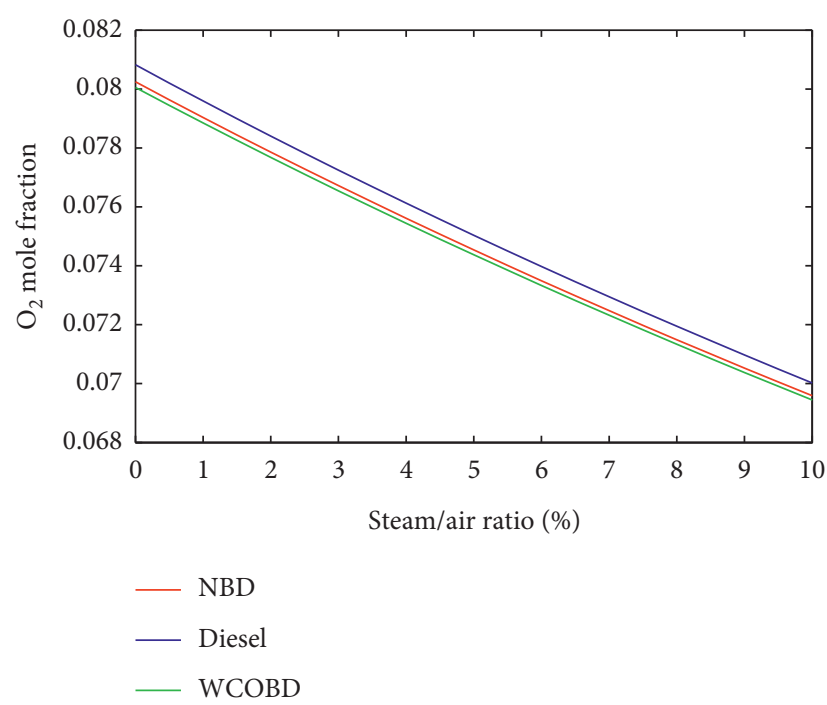

(a)

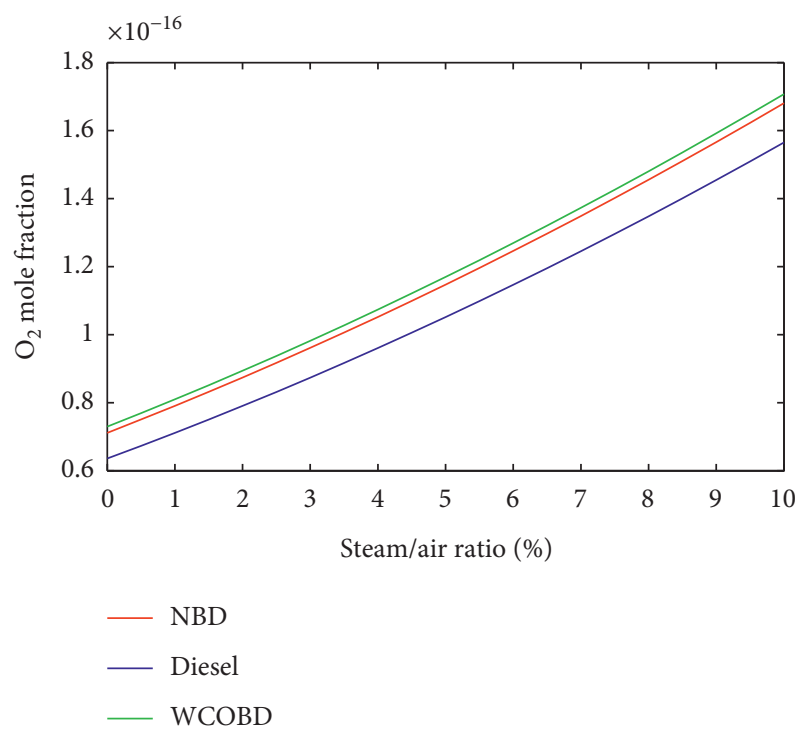

(b)

FIgURE 4: Variation of $\mathrm{O}_{2}$ equilibrium mole fractions with steam injection ratios.

$$
\begin{aligned}
& h=\frac{1}{M} \sum_{i=1}^{10} y_{i} \bar{h}_{i}, \\
& s=\frac{R_{u}}{M} \sum_{i=1}^{10} y_{i}\left(\frac{\bar{s}_{i}^{0}}{R_{u}}-\ln \left(\frac{y_{i} p}{p_{0}}\right)\right), \\
& c_{p}=\frac{1}{M} \sum_{i=1}^{10}\left(y_{i} \bar{c}_{p, i}+\bar{h}_{i} \frac{\partial y_{i}}{\partial T}-\frac{M_{T}}{M} y_{i} \bar{h}_{i}\right),
\end{aligned}
$$

where $M_{T}=\partial M / \partial T=\sum_{i=1}^{10} M_{i} \partial y_{i} / \partial T$ and $c_{p}=(\partial h / \partial T)_{p}$.
2.4. Constant-Pressure Adiabatic Flame Temperature. The constant-pressure adiabatic flame temperature $\left(\mathrm{T}_{\mathrm{ad}}\right)$ is calculated iteratively using (47). An initial temperature is required to determine the total enthalpy of reactants $h_{u}$ :

$$
T_{a d}^{i+1}=T_{a d}^{i}-\frac{h_{u}-h}{c_{p}},
$$

where $h$ is the enthalpy of combustion products obtained by (44) and $c_{p}$ is the specific heat of the combustion products obtained by (46).

For each iteration $i, h$ and $c_{p}$ are reevaluated until an acceptable prescribed tolerance is reached. 


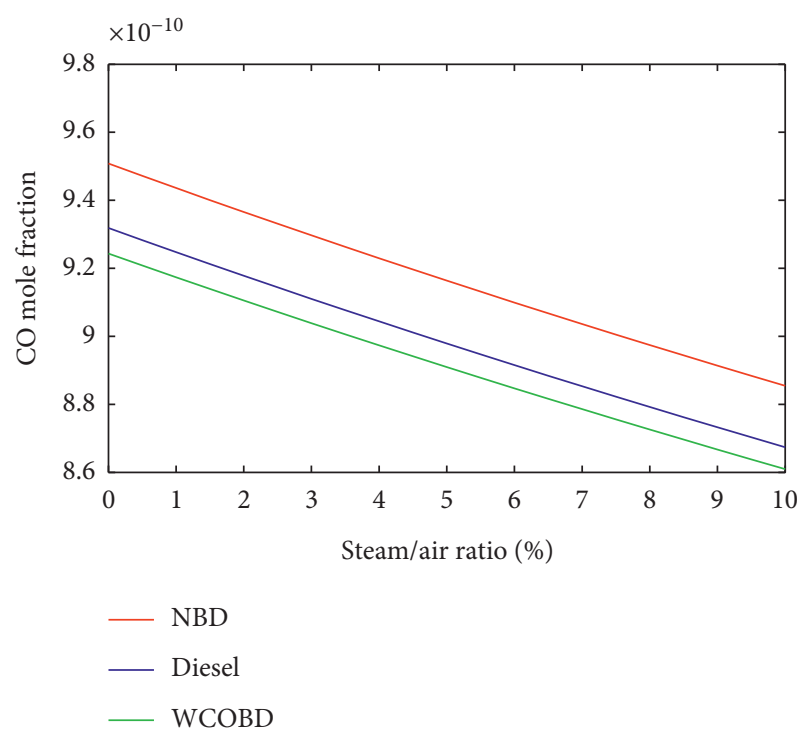

(a)

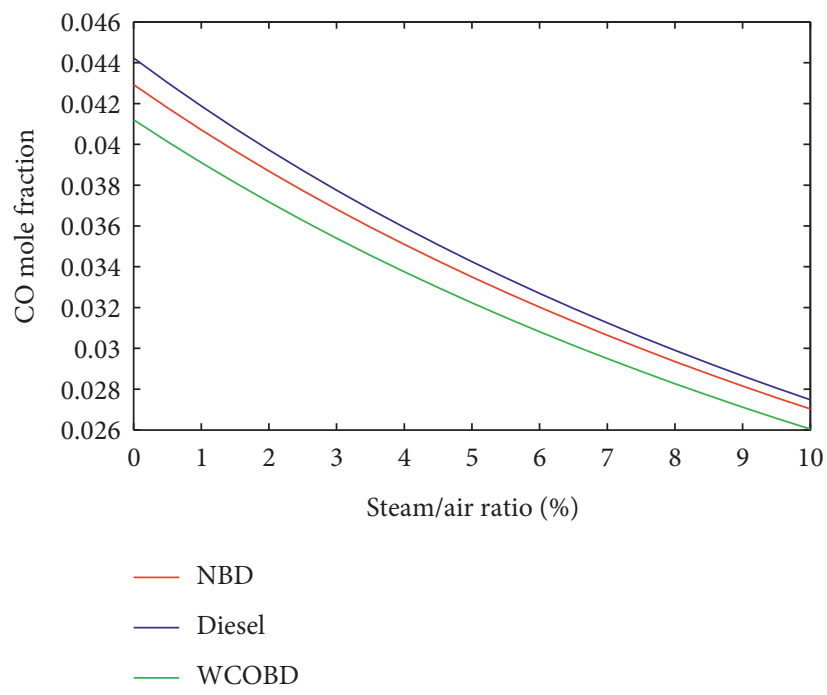

(b)

Figure 5: Variation of CO equilibrium mole fractions with steam injection ratios.

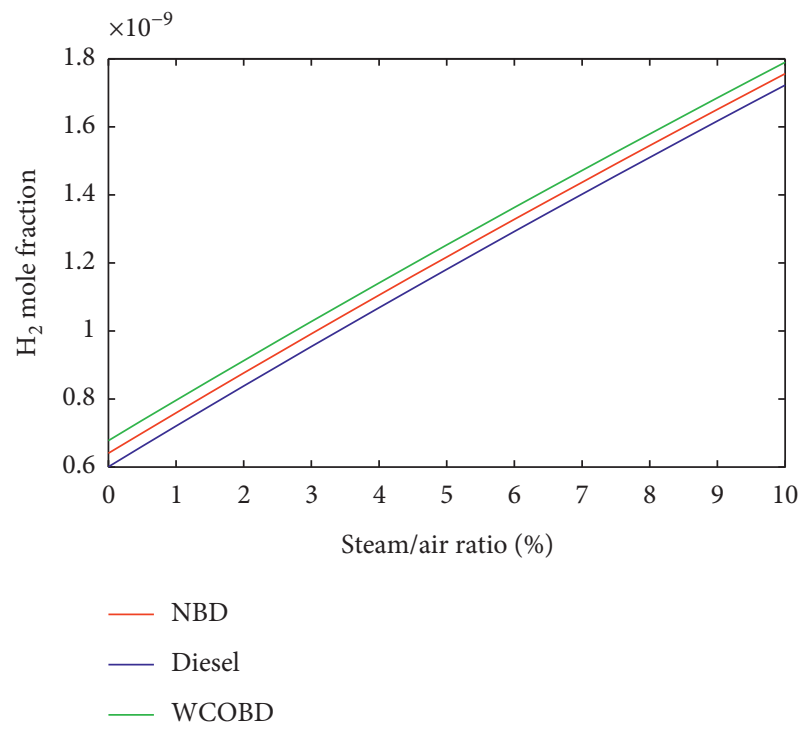

(a)

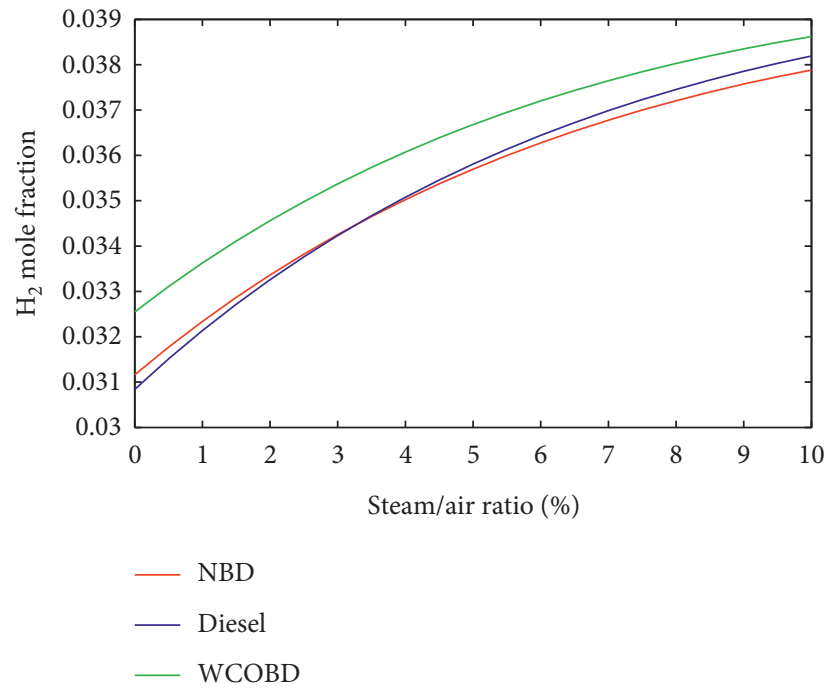

(b)

FIgURE 6: Variation of $\mathrm{H}_{2}$ equilibrium mole fractions with steam injection ratios.

2.5. Fuel Properties and Standard Specifications. The physical and chemical properties of the fuels are presented in Table 3.

Standard specifications for biodiesel and diesel fuels are shown in Table 4 according to ASTM D6751 and EN 14214.

2.6. Validation of the Model. The validation of the model is done by comparing the model results with the ones of software CEA of NASA [28] and software GASEQ [27], which use element potential method and minimization of Gibbs free energy approach, respectively. The simulations of methane with steam injection are carried out. The mole fraction of chemical equilibrium products and thermodynamic properties obtained with the model compared with the ones of software CEA of NASA and GASEQ at $\phi=0.6$ with steam injection $10 \%$ are mentioned in Table 5 and at $\phi=1.2$ with steam injection $10 \%$ are listed in Table 6.

\section{Results and Discussion}

3.1. Mole Fraction of Combustion Products. Adiabatic combustion simulation with steam has been carried out for the biodiesel and the diesel fuels in order to investigate the effects 


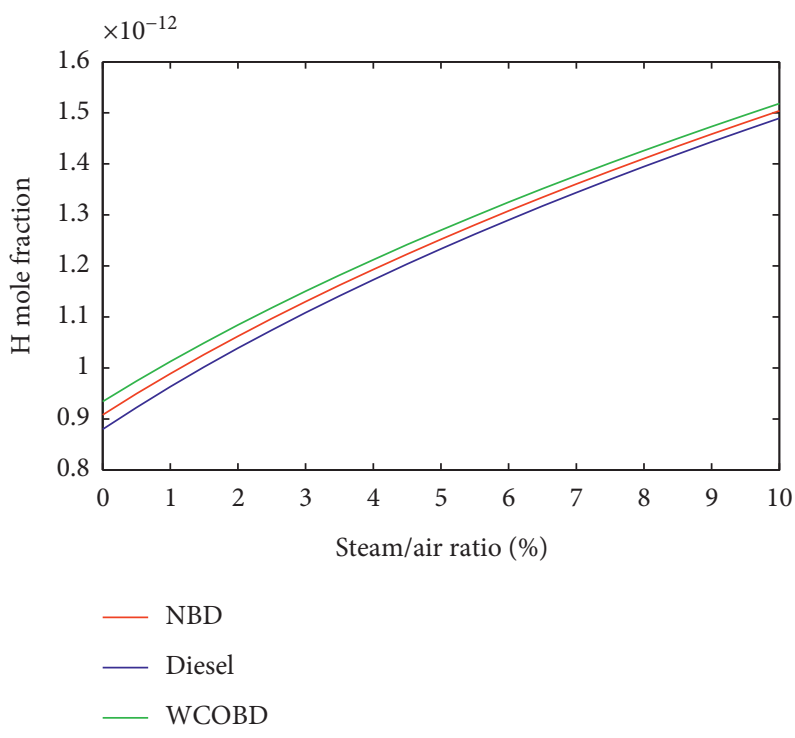

(a)

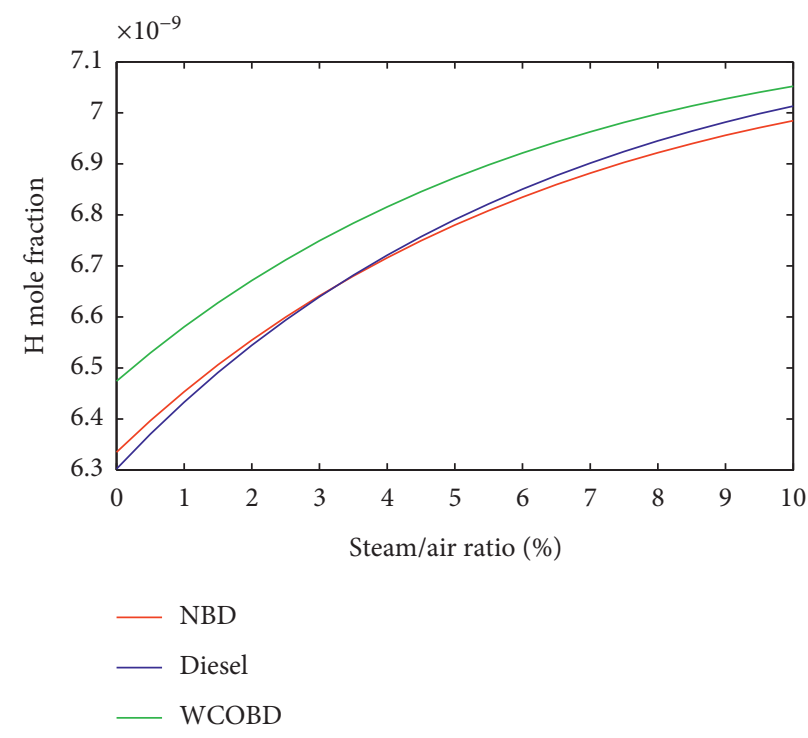

(b)

FIgURE 7: Variation of $\mathrm{H}$ equilibrium mole fractions with steam injection ratios.

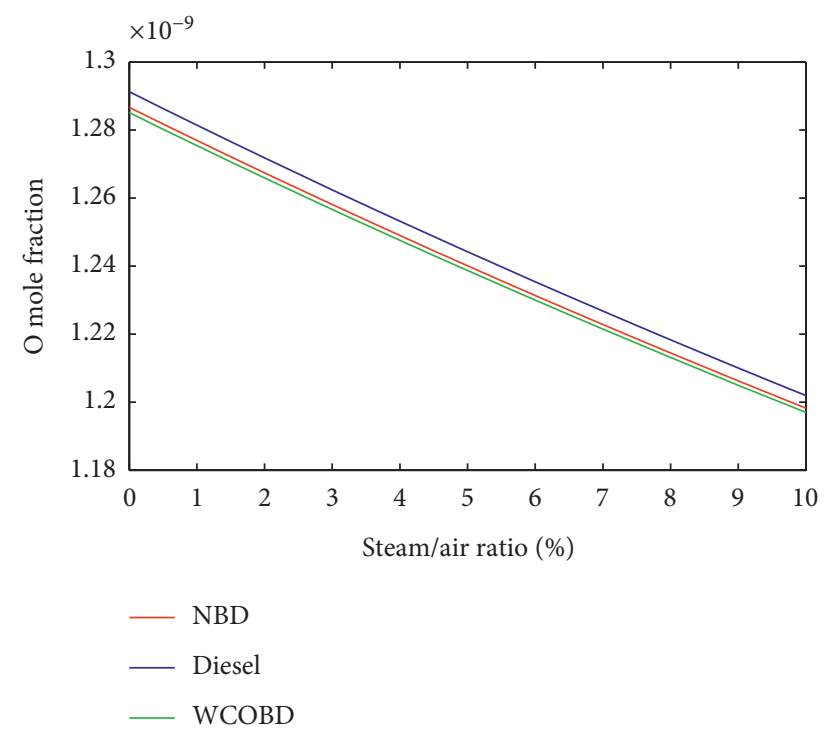

(a)

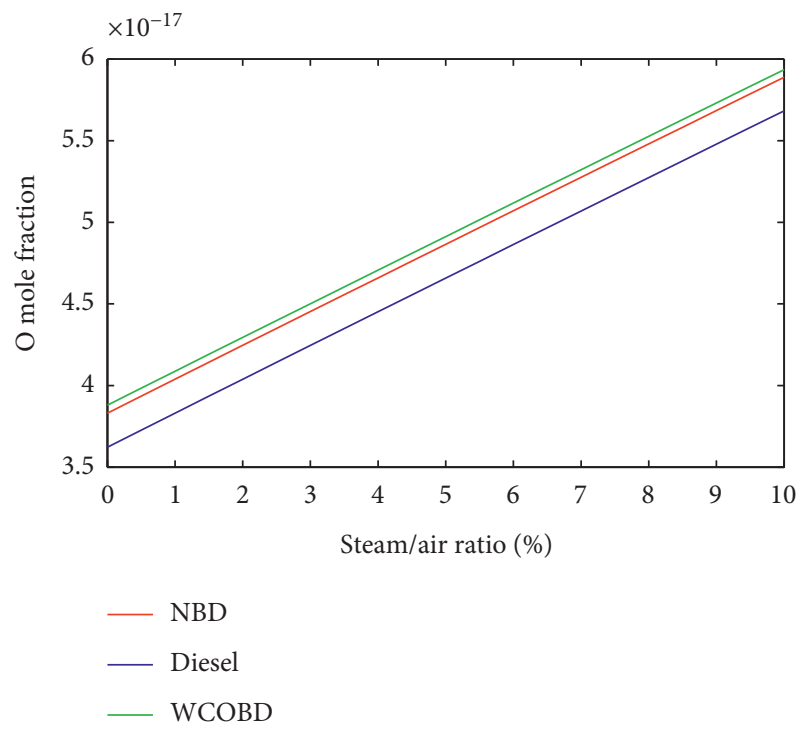

(b)

FIGURE 8: Variation of $\mathrm{O}$ equilibrium mole fractions with steam injection ratios.

of steam injection on the equilibrium combustion products and thermodynamic properties. Before the combustion, the temperature of the air and the fuel is assumed to be equal to $300 \mathrm{~K}$ and the pressure of the air and the fuel mixture is equal to the combustion chamber pressure. The pressure inside the combustion chamber is $30 \mathrm{~atm}$, which is supposed to be the pressure of injection steam. The temperature of injected steam is $300^{\circ} \mathrm{C}$. The temperature of the unburned mixture is found by assuming a thermal equilibrium amongst the reactants. Initial temperature is obtained from the thermal equilibrium of fuel-air and steam mixture.
The results have been comparatively presented for lean and rich combustion with increasing steam injection from $0 \%$ to $10 \%$.

Figures $1(\mathrm{a})$ and $1(\mathrm{~b})$ show the $\mathrm{CO}_{2}$ equilibrium mole fractions with steam injection ratios and they decrease remarkably with increasing steam injection ratios. NBD gives the highest results, while WCOBD presents the lowest results. Kayadelen [26] obtained the same behaviour in his study.

Figures 2(a) and 2(b) illustrate the $\mathrm{H}_{2} \mathrm{O}$ equilibrium mole fractions with steam injection ratios. It is clear that the 


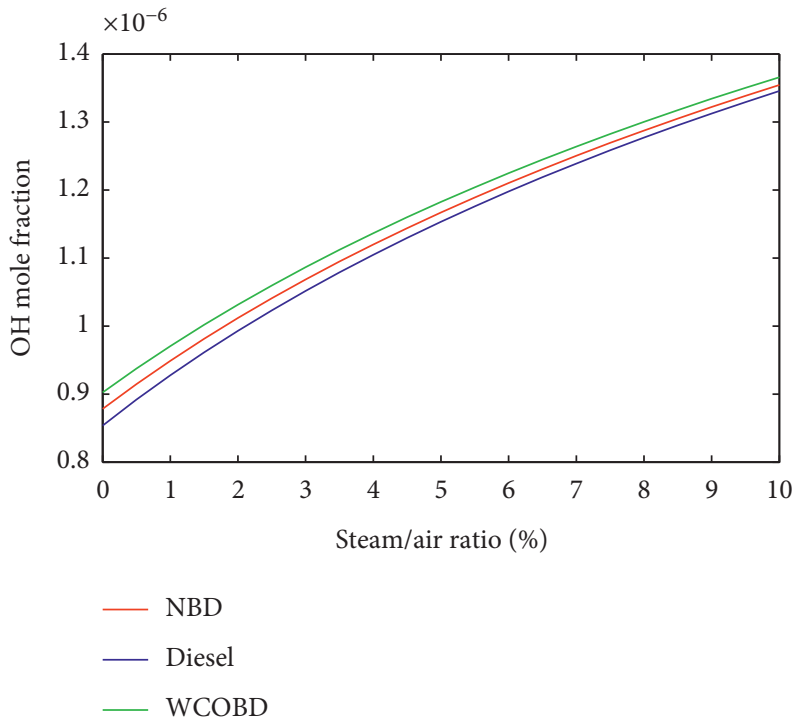

(a)

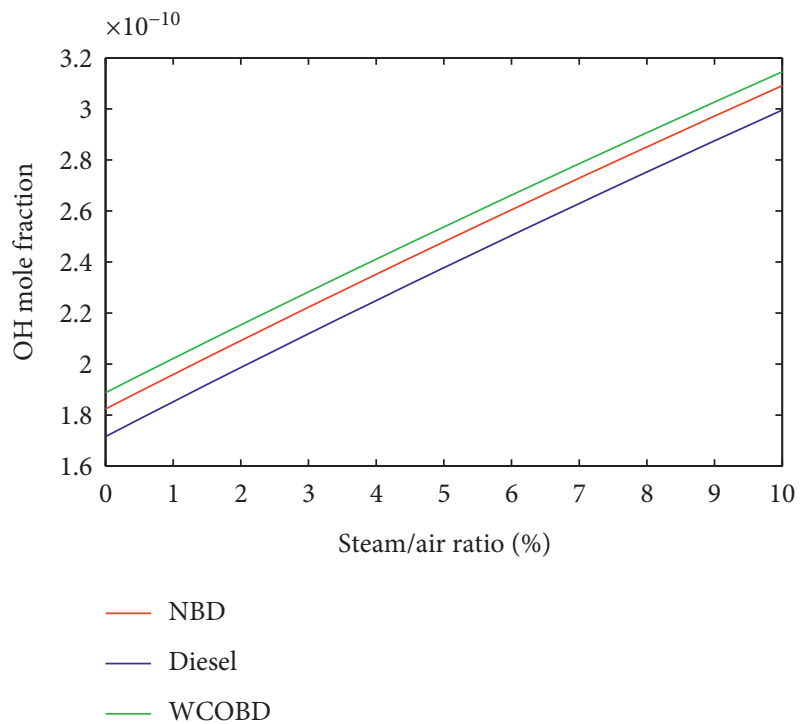

(b)

FIgURE 9: Variation of $\mathrm{OH}$ equilibrium mole fractions with steam injection ratios.

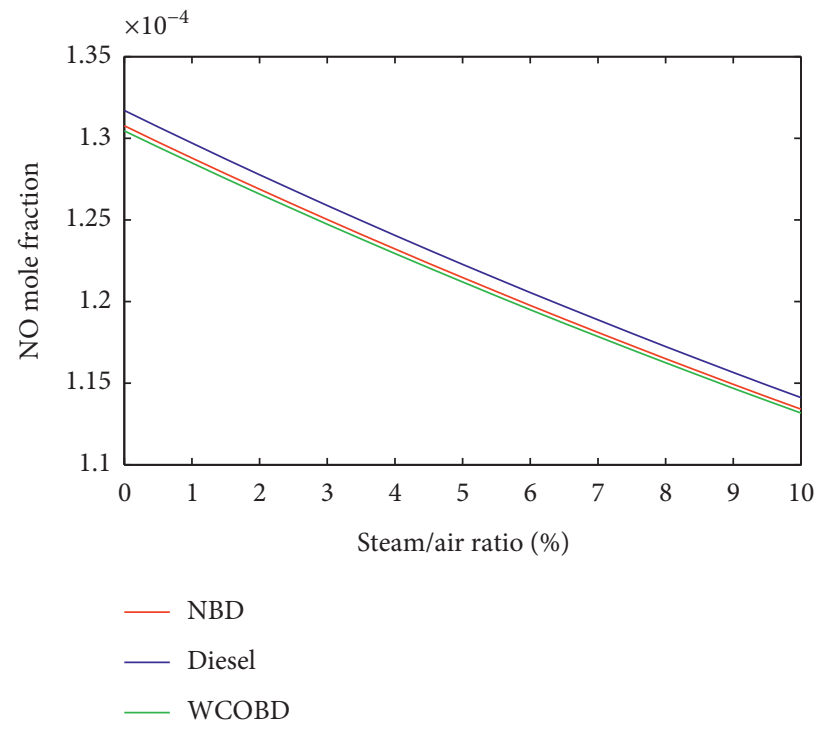

(a)

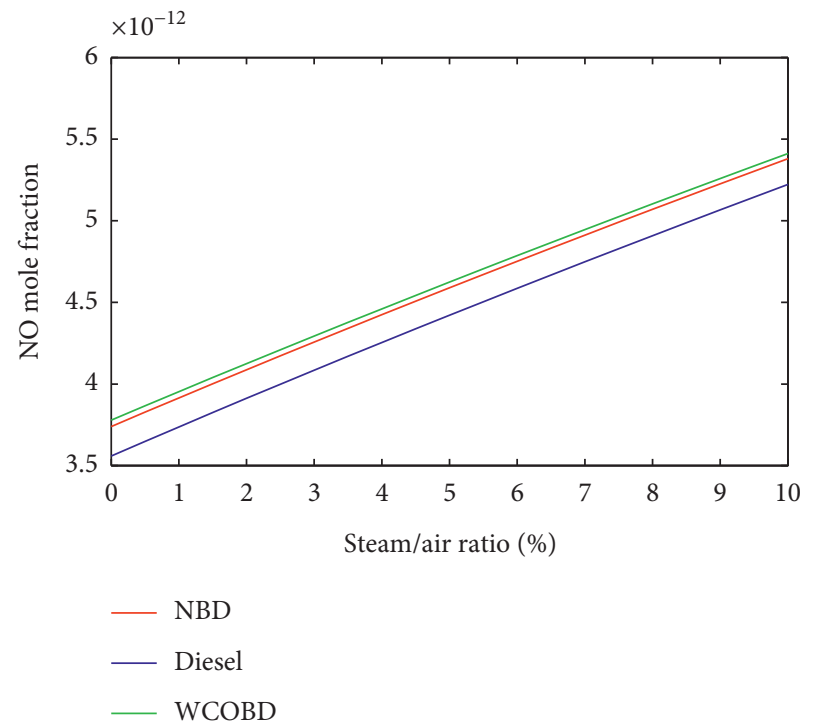

(b)

FIgURE 10: Variation of NO equilibrium mole fractions with steam injection ratios.

$\mathrm{H}_{2} \mathrm{O}$ equilibrium mole fraction increases with increasing steam injection ratios. The maximum $\mathrm{H}_{2} \mathrm{O}$ equilibrium mole fraction is obtained with WCOBD and the minimum $\mathrm{H}_{2} \mathrm{O}$ equilibrium mole fraction is observed with diesel fuel. The reason is the WCOBD has the lowest $\alpha / \beta$ ratio and diesel fuel has the highest $\alpha / \beta$ ratio. The smaller the $\alpha / \beta$ ratio is, the larger the $\mathrm{H}_{2} \mathrm{O}$ equilibrium mole fraction is.

Figures 3(a) and 3(b) illustrate the $\mathrm{N}_{2}$ equilibrium mole fractions with steam injection ratios. It is clear that the $\mathrm{N}_{2}$ equilibrium mole fraction decreases with increasing steam injection ratios. The maximum $\mathrm{N}_{2}$ equilibrium mole fraction is obtained with diesel fuel and the minimum $\mathrm{N}_{2}$ equilibrium mole fraction is observed with WCOBD. The reason is the
WCOBD has the lowest $\alpha / \beta$ ratio and diesel fuel has the highest $\alpha / \beta$ ratio.

Figures 4(a) and 4(b) shows the $\mathrm{O}_{2}$ equilibrium mole fractions with steam injection ratios. It is clear that the $\mathrm{O}_{2}$ equilibrium mole fraction decreases with increasing steam injection ratios in the case of lean combustion. The maximum $\mathrm{O}_{2}$ equilibrium mole fraction is obtained with diesel fuel and the minimum $\mathrm{O}_{2}$ equilibrium mole fraction is observed with WCOBD. The $\mathrm{O}_{2}$ equilibrium mole fraction is much lower in rich combustion due to lower oxygen concentration compared to lean combustion. The maximum $\mathrm{O}_{2}$ equilibrium mole fraction occurs with WCOBD and the minimum $\mathrm{O}_{2}$ equilibrium mole fractions occurs with diesel 


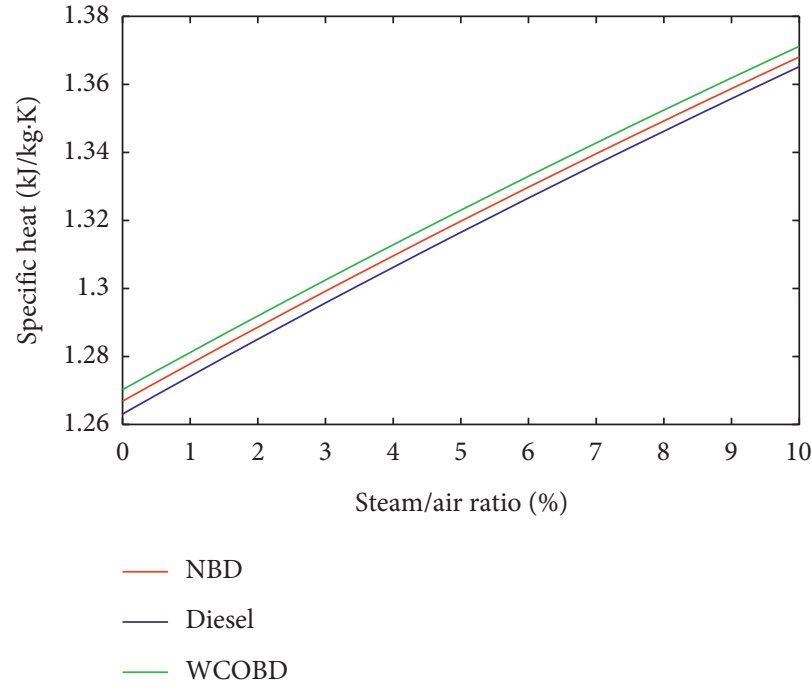

(a)

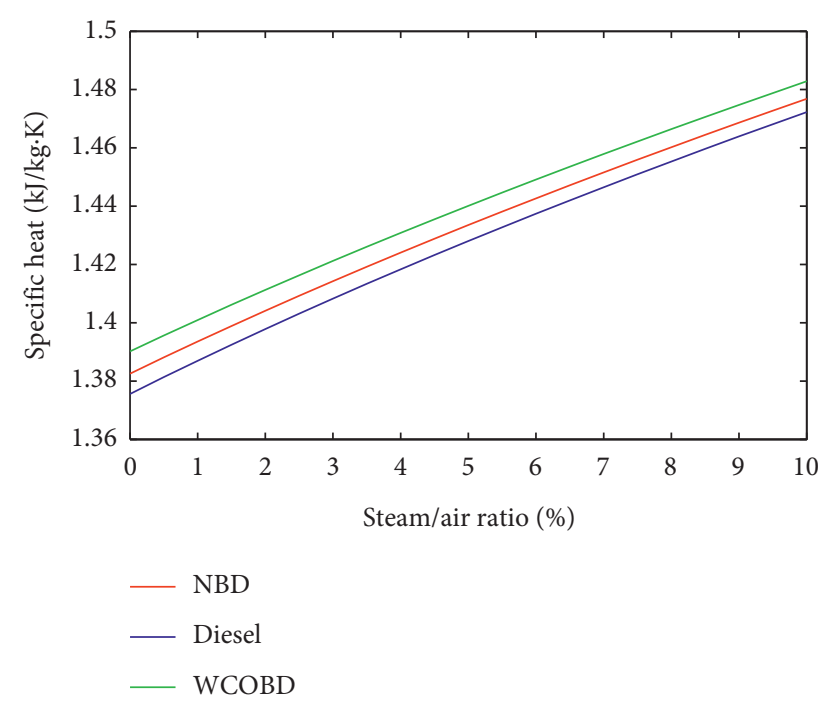

(b)

FIGURE 11: Variation of gas mixture specific heat with steam injection ratios.

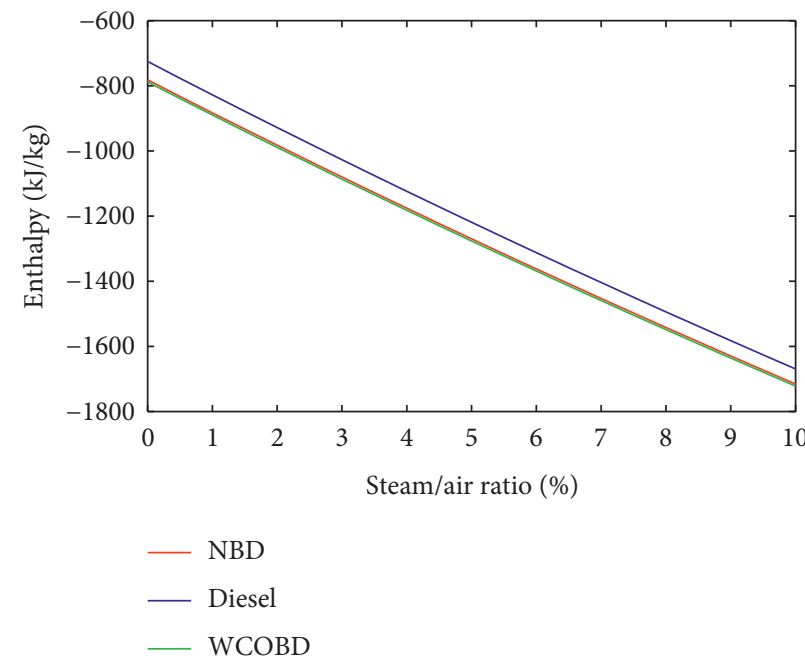

(a)

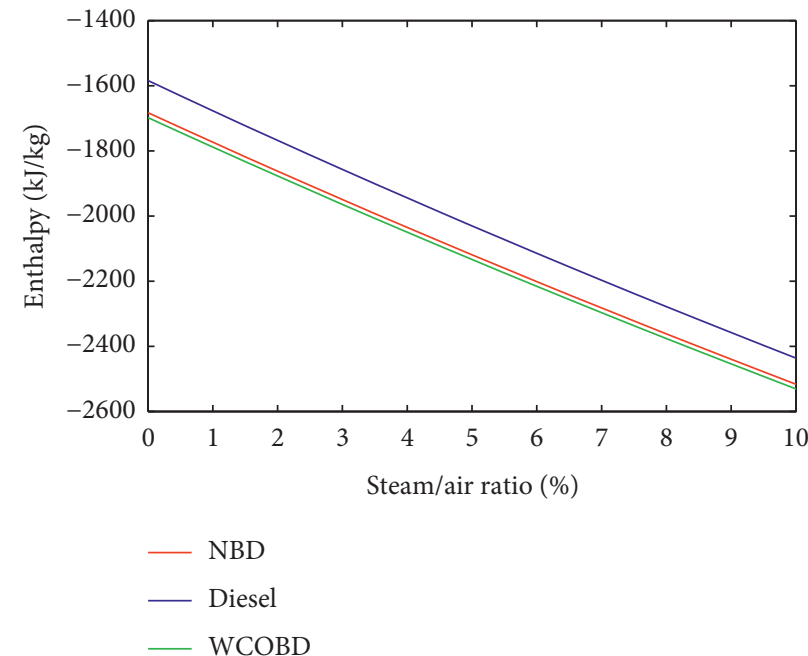

(b)

FIgURE 12: Variation of gas mixture enthalpy with steam injection ratios.

fuel in the case of rich combustion. The influence of the steam injection has the similar trend in Figures 5(a) and 5(b).

Figures 6(a) and 6(b) show the $\mathrm{CO}$ equilibrium mole fractions with steam injection ratios. The $\mathrm{CO}$ equilibrium mole fraction decreases with increasing steam injection ratios. The maximum $\mathrm{CO}$ equilibrium mole fraction is observed with diesel fuel and the minimum CO equilibrium mole fraction is observed with WCOBD in the case of rich combustion. The maximum $\mathrm{CO}$ equilibrium mole fraction is obtained with NBD and the minimum CO equilibrium mole fraction is observed with WCOBD in the case of lean combustion.

Figures $7(\mathrm{a})$ and $7(\mathrm{~b})$ show the $\mathrm{H}_{2}$ equilibrium mole fractions with steam injection ratios which increase in both rich and lean combustions. The combustion of WCOBD gives the highest $\mathrm{H}_{2}$ equilibrium mole fraction. The influence of the steam injection has the similar trend in Figures 8(a) and $8(\mathrm{~b})$.

Figures $9(\mathrm{a})$ and $9(\mathrm{~b})$ demonstrate the $\mathrm{OH}$ equilibrium mole fractions with steam injection ratios. The $\mathrm{OH}$ equilibrium mole fractions increase slightly with increasing steam injection ratios in rich and lean combustion. WCOBD releases the highest $\mathrm{OH}$ equilibrium mole fractions while diesel fuel releases the lowest $\mathrm{OH}$ equilibrium mole fractions in both rich and lean combustions. Figures 10(a) and 10(b) demonstrate the NO equilibrium mole fractions with steam injection ratios. The $\mathrm{NO}$ equilibrium mole fractions decrease with increasing steam injection ratios in lean combustion. Diesel fuel releases the highest NO equilibrium mole 


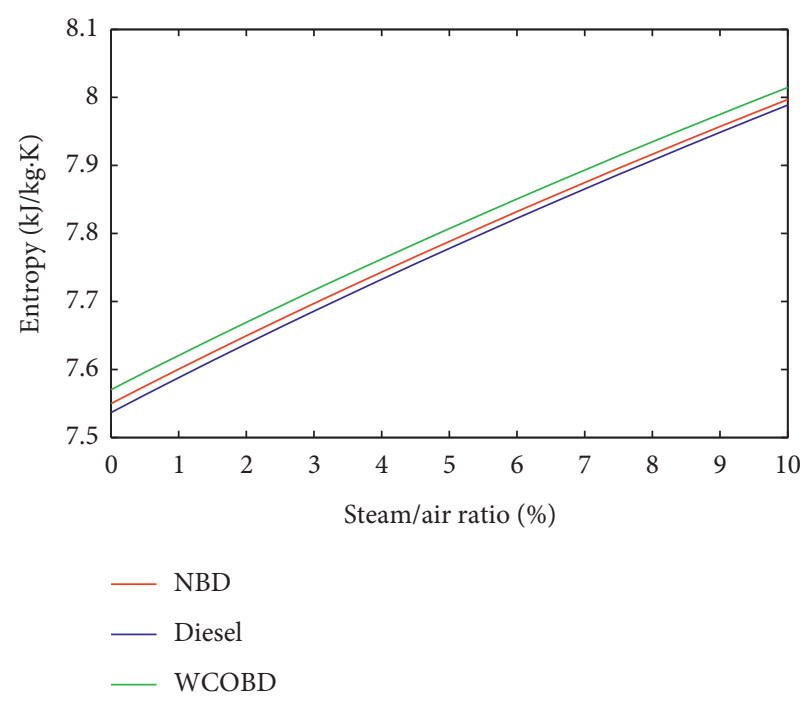

(a)

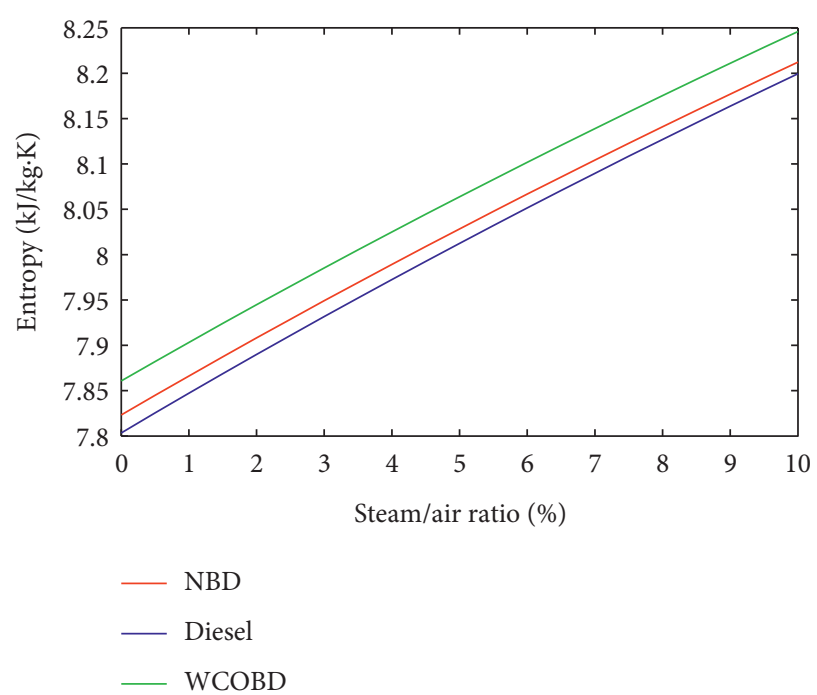

(b)

FIGURE 13: Variation of gas mixture entropy with steam injection ratios.

fractions, while WCOBD releases the lowest NO equilibrium mole fractions in lean combustions.

\subsection{Thermodynamic Properties of Combustion Products.} The specific heat and the enthalpy of the mixture of the gases increase with the steam injection ratios due to the specific heat of superheated steam which is higher than the one of air at that temperature condition. Kayadelen [26] obtained the same behaviour in his study.

Figures 11(a) and 11(b) show the variation of specific heats of combustion products with respect to steam injection ratios. Higher specific heats are obtained in the rich combustions compared to the lean combustions. The highest specific heats are seen with WCOBD and the lowest specific heats are obtained with diesel fuel. In both combustions, specific heats increase with increasing steam injection ratios because the specific heat of the steam is much more than the ones of the combustion products at the same temperature except the specific heat of $\mathrm{CO}_{2}$.

Figures 12(a) and 12(b) show the variation of enthalpy of combustion products with respect to steam injection ratios. Higher enthalpies of combustion products are obtained in the lean combustions compared to the rich combustions. The highest enthalpies of combustion products are seen with diesel fuel and the lowest enthalpies of combustion products are obtained with WCOBD. In both combustions, enthalpy of combustion products decreases with increasing steam injection ratios due to the enthalpy of the steam which is much less than the ones of the combustion products at the same temperature.

Figures 13(a) and 13(b) show the variation of entropy of combustion products with respect to steam injection ratios. Higher entropies of combustion products are obtained in the rich combustions compared to the lean combustions. The highest entropies of combustion products are seen with
WCOBD and the lowest entropies of combustion products are obtained with diesel fuel. In both combustions, entropy of combustion products increases with increasing steam injection ratios.

\section{Conclusion}

The equilibrium combustion model is used to provide mole fractions and thermodynamic properties of combustion products in chemical equilibrium. Equilibrium mole fractions and the adiabatic flame temperature are necessary for estimating thermodynamic properties of exhaust gases and for providing key data to obtain nonequilibrium mole fractions. The precise calculation of thermodynamic properties is necessary for accurate performance estimations of internal combustion engines. The influences of steam injection on equilibrium combustion products and thermodynamic properties of diesel fuel and biodiesels have been modelled.

The equilibrium mole fractions and thermodynamic properties of combustion products showed good agreement with the results obtained from CEA of NASA and GASEQ using methane.

The highest $\mathrm{CO}_{2}$ equilibrium mole fractions are seen with NBD, and the lowest ones are formed with WCOBD. The reduction rate of NO is higher for biodiesel fuels as compared with the one of diesel fuel in lean combustion conditions. Thus, the steam injection ratios can be used for biodiesel fuels in order to lower NO equilibrium combustion products in the lean combustion conditions.

The model can be a recourse tool for researchers studying fuels, surrogates, emissions, and internal combustion modelling due to its accuracy and convenience.

The equilibrium mole fractions are used in combustion engineering, for example, in chemical kinetics to look for a reference point and in parametric emission monitoring systems to estimate the emissions of power systems. 
Simulations of any combustion process including exhaust gas recirculation, supplementary firing, steam injection, water injection, fuel emulsion, and reheat process in gas turbines can easily be conducted with higher accuracy and speed by integrating this model to the thermodynamic models.

\section{Nomenclature}

ASTM: American Society of Testing and Materials

EGR: Exhaust gas recirculation

EN: European norms

$h$ : $\quad$ Specific enthalpy, $\mathrm{kJ} \cdot \mathrm{kg}^{-1}$

M: $\quad$ Molecular weight of the mixture, $\mathrm{kg} \cdot \mathrm{kmol}^{-1}$

NASA: National Aeronautics and Space Administration

$p: \quad$ Pressure, $\mathrm{Pa}$

PM: $\quad$ Particulate matter

$s: \quad$ Specific entropy, $\mathrm{kJ} \cdot \mathrm{kg}^{-1} \cdot \mathrm{K}^{-1}$

T: $\quad$ Temperature, $\mathrm{K}$

$x$ : $\quad$ Number of moles injected $\mathrm{H}_{2} \mathrm{O}$

$y i$ : $\quad$ Mole fraction of species $i$.

Greek Letters

$\alpha$ : Atomic number of carbon for fuels

$\beta$ : Atomic number of hydrogen for fuels

$\gamma$ : Atomic number of oxygen for fuels

$\delta$ : Atomic number of nitrogen for fuels

$\varepsilon$ : Molar fuel/air ratio

$\phi$ : Equivalence ratio

vi: Number of moles for product species $i$.

Subscripts

a: Air

$f:$ Fuel

s: Stoichiometric.

\section{Data Availability}

No data were used in this research. The authors carried out computational simulation to obtain the results of the research.

\section{Conflicts of Interest}

The authors declare that there are no conflicts of interest.

\section{References}

[1] A. E. Atabani, A. S. Silitonga, I. A. Badruddin, T. M. I. Mahlia, H. H. Masjuki, and S. Mekhilef, "A comprehensive review on biodiesel as an alternative energy resource and its characteristics," Renewable and Sustainable Energy Reviews, vol. 16, no. 4, pp. 2070-2093, 2012.

[2] M. Elkelawy, H. A. E. Bastawissi, K. K. Esmaeil et al., "Experimental studies on the biodiesel production parameters optimization of sunflower and soybean oil mixture and DI engine combustion, performance, and emission analysis fueled with diesel/biodiesel blends," Fuel, vol. 255, Article ID 115791, 2019.

[3] M. Mofijur, H. H. Masjuki, M. A. Kalam, and A. E. Atabani, "Evaluation of biodiesel blending, engine performance and emissions characteristics of Jatropha curcas methyl ester: Malaysian perspective," Energy, vol. 55, pp. 879-887, 2013.
[4] S. M. Palash, H. H. Masjuki, M. A. Kalam, B. M. Masum, A. Sanjid, and M. J. Abedin, "State of the art of NOx mitigation technologies and their effect on the performance and emission characteristics of biodiesel-fueled compression ignition engines," Energy Conversion and Management, vol. 76, pp. 400-420, 2013.

[5] B. Ashok, K. Nanthagopal, A. K. Jeevanantham, P. Bhowmick, D. Malhotra, and P. Agarwal, "An assessment of Calophyllum inophyllum biodiesel fuelled diesel engine characteristics using novel antioxidant additives," Energy Conversion and Management, vol. 148, pp. 93-43, 2017.

[6] M. Gülüm and A. Bilgin, "Two-term power models for estimating kinematic viscosities of different biodiesel-diesel fuel blends," Fuel Processing Technology, vol. 149, pp. 121-130, 2016.

[7] A. Demirbas, "Importance of biodiesel as transportation fuel," Energy Policy, vol. 35, pp. 4661-4670, 2007.

[8] R. O. Dunn and B. R. Moser, "Cold weather properties and performance of biodiesel," The Biodiesel Handbook, Taylor \& Francis, vol. 30, pp. 83-121, , Abingdon, UK, 2005.

[9] P. Hellier, M. Talibi, A. Eveleigh, and N. Ladommatos, "An overview of the effects of fuel molecular structure on the combustion and emissions characteristics of compression ignition engines," Proceedings of the Institution of Mechanical Engineers, Part D: Journal of Automobile Engineering, vol. 232, no. $1,2018$.

[10] P. Tamilselvan, N. Nallusamy, and S. Rajkumar, "A comprehensive review on performance, combustion and emission characteristics of biodiesel fuelled diesel engines," Renewable and Sustainable Energy Reviews, vol. 79, pp. 1134-1159, 2017.

[11] M. Gülüm, F. K. Onay, and A. Bilgin, "Comparison of viscosity prediction capabilities of regression models and artificial neural networks," Energy, vol. 161, pp. 361-369, 2018.

[12] L. Coniglio, H. Bennadji, P. A. Glaude, O. Herbinet, and F. Billaud, "Combustion chemical kinetics of biodiesel and related compounds (methyl and ethyl esters): experiments and modeling-advances and future refinements," Progress in Energy and Combustion Science, vol. 39, pp. 340-382, 2013.

[13] P. Visconti, P. Primiceri, L. Strafella, A. P. Carlucci, and A. Ficarella, "Morphological analysis of injected sprays of different bio-diesel fuels by using a common rail setup controlled by a programmable electronic system," International Journal of Automotive and Mechanical Engineering, vol. 14, no. 1, pp. 3849-3871, 2017.

[14] S. K. Nayak and P. C. Mishra, "Emission from a dual fuel operated diesel engine fuelled with Calophyllum inophyllum biodiesel and producer gas," International Journal of Automotive and Mechanical Engineering, vol. 14, no. 1, pp. 39543969, 2017.

[15] M. R. Shukri, M. M. Rahman, D. Ramasamy, and K. Kadirgama, "Artificial neural network optimization modeling on engine performance of diesel engine using biodiesel fuel," International Journal of Automotive and Mechanical Engineering, vol. 11, pp. 2332-2347, 2015.

[16] M. M. Hasan, M. M. Rahman, and K. Kadirgama, "A review on homogeneous charge compression ignition engine performance using biodiesel-diesel blend as a fuel," International Journal of Automotive and Mechanical Engineering, vol. 11, pp. 2199-2211, 2015.

[17] M. Rashidi, "Calculation of equilibrium composition in combustion products," Chemical Engineering and Technology, vol. 20, no. 6, pp. 571-575, 1997.

[18] R. Way, "Methods for determination of composition and thermodynamic properties of combustion products for 
internal combustion engine calculations," Proceedings of the Institution of Mechanical Engineers, vol. 190, pp. 687-697, 1976.

[19] J. B. Heywood, Internal Combustion Engine Fundamentals, McGraw-Hill, New York Cty, NY, USA, 1988.

[20] G. Gonca, "Investigation of the influences of steam injection on the equilibrium combustion products and thermodynamic properties of bio fuels (biodiesels and alcohols)," Fuel, vol. 144, pp. 244-258, 2015.

[21] C. V. Ngayihi Abbe, R. Danwe, and R. Nzengwa, "Comparative numerical study of four biodiesel surrogates for application on diesel 0D phenomenological modeling," Journal of Combustion, vol. 2016, Article ID 3714913, 11 pages, 2016.

[22] Y. Ust and H. K. Kayadelen, "Prediction of equilibrium products and thermodynamic properties in $\mathrm{H}_{2} \mathrm{O}$ injected combustion for $\mathrm{C}_{\alpha} \mathrm{H}_{\beta} \mathrm{O}_{\gamma} \mathrm{N}_{\delta}$ type fuels," Fuel, vol. 113, pp. 389-401, 2013.

[23] C. Rakopoulos, D. Rakopoulos, and D. Kyritsis, "Development and validation of a comprehensive two-zone model for combustion and emissions formation in a DI diesel engine," International Journal of Energy Research, vol. 27, no. 14, pp. 1221-1249, 2003

[24] F. Diotallevi, Development of a Multi-Zone Model for Nox Formation in Diesel Engines, KTH Industrial Engineering and Management, Stockolm, Sweden, 2007.

[25] D. Mourya and V. Roy, "Combustion modeling and simulation of combustion emissions for diesel engine operating on the blends of jatropha biodiesel and diesel," International Journal of Engineering Science and Technology, vol. 4, no. 4, pp. 1373-1381, 2012.

[26] H. K. Kayadelen, "A multi-featured model for estimation of thermodynamic properties, adiabatic flame temperature and equilibrium combustion products of fuels, fuel blends, surrogates and fuel additives," Energy, vol. 143, pp. 241-256, 2018.

[27] Morley C., Gaseq chemical equilibrium program ver 0.07.0009.

[28] S. Gordon and B. J. McBride, Computer Program for Calculation of Complex Chemical Equilibrium Compositions and Applications, NASA, Washington, DC, USA, 1994.

[29] M. Canakci, "Combustion characteristics of a turbocharged DI compression ignition engine fueled with petroleum diesel fuels and biodiesel," Bioresource Technology, vol. 98, no. 6, pp. 1167-1175, 2007.

[30] S. Awad, E. G. Varuvel, K. Loubar, and M. Tazerout, "Single zone combustion modeling of biodiesel from wastes in diesel engine," Fuel, vol. 106, pp. 558-568, 2013.

[31] C. R. Ferguson, Internal Combustion Engines: Applied Thermosciences, John Wiley, Hoboken, NJ, USA, 1986.

[32] C. Olikara and G. L. Borman, A Computer Program for Calculating Properties of Equilibrium Combustion Products with Some Applications to IC Engines, Society of Automotive Engineers, Warrendale, PA, USA, 1975.

[33] S. Gordon and B. J. McBride, Computer Program for Calculation of Complex Chemical Equilibrium Composition, Rocket Performance, Incident and Reflected Shocks, and Chapman Jouguet Detonations, NASA, Washington, DC, USA, 1971.

[34] National Bureau of Standards, JANAF Thermochemical Tables, National Bureau of Standards, Washington DC, USA, 1971.

[35] M. Gülüm, M. Kadir Yesilyurt, and A. Bilgin, "The performance assessment of cubic spline interpolation and response surface methodology in the mathematical modeling to optimize biodiesel production from waste cooking oil," Fuel, vol. 255, Article ID 115778, 2019.
[36] M. K. Yesilyurt, Z. Yilbasi, and M. Aydin, "The performance, emissions, and combustion characteristics of an unmodified diesel engine running on the ternary blends of pentanol/ safflower oil biodiesel/diesel fuel," Journal of Thermal Analysis and Calorimetry, vol. 140, no. 6, 2020. 